$\begin{array}{ll} & \text { Etnográfica } \\ \text { etnográfica } & \text { Revista do Centro em Rede de Investigação em }\end{array}$

Antropologia

vol. $15(2) \mid 2011$

Vol. $15(2)$

\title{
O fantasma de Evans-Pritchard: diálogos da antropologia com a sua história
}

The ghost of Evans-Pritchard: anthropology's dialogues with its own history

\section{Frederico Delgado Rosa}

\section{(2) OpenEdition}

\section{Journals}

\section{Edição electrónica}

URL: https://journals.openedition.org/etnografica/965

DOI: 10.4000/etnografica.965

ISSN: 2182-2891

\section{Editora}

Centro em Rede de Investigação em Antropologia

\section{Edição impressa}

Data de publição: 1 junho 2011

Paginação: 337-360

ISSN: 0873-6561

\section{Refêrencia eletrónica}

Frederico Delgado Rosa, «O fantasma de Evans-Pritchard: diálogos da antropologia com a sua história», Etnográfica [Online], vol. 15 (2) | 2011, posto online no dia 27 setembro 2012, consultado o 10 fevereiro 2022. URL: http://journals.openedition.org/etnografica/965 ; DOI: https://doi.org/10.4000/ etnografica.965 


\title{
O fantasma de Evans-Pritchard: diálogos da antropologia com a sua história
}

Frederico Delgado Rosa

\begin{abstract}
Tomando como estudo de caso a monografia de Sharon Hutchinson sobre os nuer, o presente artigo explora os quiproquós do diálogo entre a antropologia contemporânea e os clássicos, procurando detetar certas genealogias invisíveis que remontam aos funcionalistas britânicos, e nomeadamente a Evans-Pritchard. Procede a um esbatimento de certas oposições explícitas entre o presente e o passado da antropologia, revelando que as noções clássicas perpassam de forma subterrânea o discurso daqueles que dizem rejeitá-las e que muitas das preocupações atuais já tinham expressão nas etnografias modernas. É demonstrado que as abordagens estáticas - como a de Evans-Pritchard - tinham uma componente histórica e que a antropologia social britânica teve as suas respostas teóricas e metodológicas para as transformações dos contextos africanos sob domínio colonial.
\end{abstract}

PALAVRAS-CHAVE: história da antropologia, nuer, Evans-Pritchard, funcionalismo, Sharon Hutchinson, colonialismo.

\section{EM SENTIDO MAIS OU MENOS FIGURADO, CONSOANTE O QUE SE ENTENDA} pelo termo, muitos antropólogos de hoje vivem uma curiosa relação de etnicidade com os do passado. Não os reconhecem como pertencendo ao mesmo grupo e fazem questão de sublinhar as diferenças que os separam. A expressão "antropologia clássica" é correntemente usada para etiquetar o outro grupo de forma amalgamada, como acontece em muitas relações desse tipo. O olhar exterior exerce o seu poder de demarcação com tanto mais supremacia quanto a barreira da morte rouba aos visados o direito de resposta. Este jogo de forças desigual reflete-se numa "visão triunfante da antropologia", como se os seus praticantes contemporâneos fossem necessariamente mais esclarecidos e mais conhecedores do Homem e dos objetivos legítimos da Ciência do Homem do que o foram os clássicos - também chamados de modernos -, alegadamente 
cúmplices ou pelo menos vítimas do seu próprio comprometimento ideológico com os poderes e os saberes do colonizador branco. ${ }^{1}$ Nas palavras de Herbert Lewis, os antropólogos que hoje se demarcam de forma vincada dos seus predecessores da primeira metade do século XX tendem a infligir-lhes o mesmo tratamento que estes supostamente tinham infligido aos povos que estudavam: "essencializar, totalizar, estereotipar, alterizar... inventar uma coisa que nunca existiu de forma a dominá-la" (Lewis 1998: 718, 726; todas as traduções são minhas).

Um dos principais critérios dessa diferença construída entre o "nós" e os "outros" é o conceito de cultura, que no passado teria sido responsável por uma visão das sociedades humanas como ilhas intemporais, sem conflitos nem variações internas, distintas e distanciadas umas das outras, tão-pouco com qualquer referência ao contexto colonial em que eram observadas. É interessante que num capítulo justamente intitulado "What is ethnicity?", de Thomas Eriksen, se encontre reproduzida a afirmação frequente - já tão rotineira na produção contemporânea que dispensa compilação sistemática - segundo a qual "a antropologia clássica exemplificada pelas obras de Malinowski, Boas, Radcliffe-Brown, Lévi-Strauss, Evans-Pritchard e outros se focalizava de forma característica em sociedades 'tribais' [...] vistas como unidades mais ou menos homogéneas, estáticas e isoladas" (Eriksen 1993: 8). Nessa breve amostra de clássicos, o nome de Franz Boas é o único que representa a antropologia culturalista norte-americana. Talvez seja fácil depreender, pelo seu lugar de disseminador do paradigma, que os seus muitos discípulos se veem implicados por tabela. E o facto é que, apesar de mortos, têm tido uma defensora na veterana americanista e historiadora da antropologia Regna Darnell, cujo livro de 2001, Invisible Genealogies: A History of Americanist Anthropology, desmistifica as acusações que lhes são dirigidas e revela a que ponto foram eles próprios precursores, inclusive através de acesas disputas internas, das subtilezas pós-modernas em torno do conceito de cultura e da escrita antropológica.

Chega a ser desconcertante que a ideia de cultura como ilha estática seja associada a uma corrente de matriz difusionista, cujo pai fundador, Franz Boas, vivia obcecado com a história das relações entre grupos vizinhos, tendo sido aliás um apóstolo da devolução da profundidade histórica aos povos ditos primitivos, em reação a certos postulados evolucionistas. Não é demais relembrar que os numerosos representantes da corrente boasiana estavam profundamente cientes da promiscuidade cultural das tribos índias da América do Norte, tanto nas diversas áreas culturais (um conceito-chave dessa era) como

I A expressão "visão triunfante da antropologia" é tomada de empréstimo a Nélia Dias, que a empregou num aceso debate final do painel "História da Antropologia: Diálogos com a Antropologia Contemporânea”, do $4 .^{\circ}$ Congresso da Associação Portuguesa de Antropologia, em Setembro de 2009. Agradeço a João Leal, Cândida Porto, Filipe Verde, Nélia Dias, José Mapril e Ricardo Roque pela leitura crítica do manuscrito, sendo quaisquer defeitos da minha inteira responsabilidade. 
nas respetivas margens, já para não falar do peso e relevância da etnografia das reservas enquanto tais e dos estudos boasianos de aculturação, a partir dos anos 1920 e com maior intensidade nas décadas seguintes. ${ }^{2}$ Para além dessa reposição da verdade, Darnell tem a ousadia de reivindicar para a história da antropologia um lugar capital na produção antropológica atual, um lugar que, no fundo, lhe foi sendo sonegado de forma involuntária pelos ensinamentos ultra-historicistas de G. W. Stocking, Jr. Contra os riscos de tornar irrelevante para os não especialistas a empresa historiográfica, impõe-se um diálogo mais consequente, mais presentista, no bom sentido da palavra, com os autores do passado: "Pretendo resgatar a história da antropologia de forma a que possa servir aos antropólogos como um meio de construção das identidades profissionais contemporâneas em continuidade com o passado" (Darnell 2001: 1).

Já em relação aos britânicos, incluindo o adotivo Malinowski, têm-lhes faltado advogados entre os vivos que se abalancem a uma empresa historiográfica de presentismo esclarecido. Os efeitos da continuada fustigação dos antigos "heróis", com destaque justamente para Malinowski, ainda se fazem sentir na comunidade antropológica contemporânea. ${ }^{3}$ Não deixa também de ser irónico que um homem cuja obra-prima de 1922 descreve uma rede instituída de trocas cerimoniais entre diversos grupos da Melanésia seja associado à tal suposta visão das sociedades como ilhas isoladas. Quanto à rejeição da história e à omissão do colonialismo, convém não esquecer que, desde o final dos anos 20, Malinowski escreveu extensamente sobre questões de contacto cultural em África e fez uma inflexão no seu próprio ceticismo em relação às abordagens diacrónicas. Em sua opinião, “opor a história à ciência é um exercício fútil e negligenciar uma ou outra torna incompleta qualquer empresa humanística" (Malinowski 1945: 33-34). Reconhecia que a mudança cultural era "um fator permanente da civilização humana em todo o lado e em todos os tempos" e salientava que a expansão colonial europeia elevava esse axioma a um novo patamar. Demarcando-se do "old anthropologist", explorou novos caminhos e passou a considerar, mesmo em relação à sua Melanésia, que um exclusivo enfoque nas instituições nativas, longe de espelhar o presente etnográfico, constituía uma reconstrução histórica e um interesse de antiquário que eventualmente obliterava "the real issues" (1945: 14, 6).

O presente artigo pretende explorar, através de um caso concreto, os quiproquós do diálogo entre os contemporâneos e os clássicos, procurando contribuir, na senda de Regna Darnell, para a descoberta de certas genealogias invisíveis que

2 Veja-se o artigo de João Leal no presente volume.

3 Seja-me permitido contar aqui um pequeno episódio pessoal a esse respeito. Enquanto professor de história da Antropologia, andei à procura de um crânio para as aulas dedicadas a grandes vultos, como Malinowski, de forma a sugerir bem humoradamente aos alunos que "lá do alto" eles nos observam. O comentário de um colega antropólogo, a quem contei a minha ideia, não se fez esperar: "Só se for para comemorar que o Malinowski está morto". 
remontam desta feita aos funcionalistas britânicos, e em particular a Edward Evans-Pritchard (1902-1973). Dedicaremos então uma especial atenção à antropóloga americana Sharon Hutchinson, que enfrentou as adversidades da terra nuer no conturbado contexto imediatamente anterior ao começo da segunda guerra civil, em 1979-83, com arriscados regressos em 1990 e 1992. O seu livro Nuer Dilemmas: Copying with Money, War, and the State, de 1996, enfileira-se na linhagem de The Nuer, no sentido em que o propósito deliberado da autora era perceber as transformações ocorridas desde o tempo de Evans-Pritchard. É certo que, mesmo após a independência do Sudão em 1955, os nuer nunca perderam atualidade, mas como o acesso ao terreno se tornou impraticável por razões de segurança, foram apenas objeto de sucessivas discussões teóricas, centradas sobretudo na releitura do decano de Oxford. Foi por sentir que os nuer estavam "enclausurados no museu" das releituras de Evans-Pritchard que Sharon Hutchinson escolheu um terreno tão difícil e perigoso. Movida pela "profunda curiosidade" de saber o que lhes tinha acontecido em cinquenta anos, propôs-se quebrar a ilusão de que estavam "acima da história e para lá da mudança" (Hutchinson 1996: 21, 32).

Num primeiro momento, iremos explorar o distanciamento teórico explícito de Sharon Hutchinson em relação à alegada ausência de história na obra de Evans-Pritchard. Faremos recuar na história da antropologia as tensões entre as abordagens estáticas e dinâmicas, bem como os vasos comunicantes entre umas e outras, em particular através das reflexões de Raymond Firth a esse respeito. Num segundo momento, analisaremos a utilização que Hutchinson faz da obra do administrador colonial do Sul do Sudão e antropólogo Paul Philip Howell, enquanto missing link histórico da experiência nuer sob o domínio britânico nos anos 40 e 50. A avaliação das relações intelectuais entre Howell e Evans-Pritchard, através das suas respetivas etnografias, levar-nos-á por fim a uma crítica do tipo de diálogo que Sharon Hutchinson, enquanto representante da antropologia contemporânea, mantém com a história da antropologia, evidenciando nomeadamente as componentes ideológicas e retóricas do afirmado contraste em relação aos "clássicos".

\section{CONSENSOS E CONTINUIDADES DA ANTROPOLOGIA SOCIAL BRITÂNICA}

É bem sabido que, nos anos 80, a obra de Evans-Pritchard passou a ser vista por muitos como um expoente da antropologia no auge do colonialismo e se tornou um objeto apetecido das desconstruções pós-modernistas. A famosa trilogia, e em particular The Nuer, foi eleita como ilustração de um estilo etnográfico que manipulava o leitor e escondia as condições muito especiais em que fora realizado o próprio trabalho de campo. $\mathrm{O}$ resultado final criava a miragem de uma realidade cultural circunscrita e intemporal - o "presente etnográfico" funcionalista - em vez de revelar as conturbadas vicissitudes da existência nuer 
sob o domínio britânico. Por exemplo, Renato Rosaldo escreveu, no seu contributo para Writing Culture, que esse tipo de abstração era notório quando Evans-Pritchard apresentava o boicote às suas perguntas como uma afirmação dos valores de sobranceria típicos dos nuer (Rosaldo 1986: 91). Ora, isto não é verdade. Bem no início do livro, Evans-Pritchard relacionou a má vontade de alguns dos seus interlocutores com o contexto colonial. Deixou claro que, no período da sua estadia, "os nuer demonstravam uma hostilidade fora do vulgar, uma vez que a sua recente derrota e as medidas tomadas pelo governo para assegurar a submissão final tinham provocado um profundo ressentimento". Esclareceu inclusive que os nuer o viam "não apenas como um estrangeiro, mas como um inimigo" (Evans-Pritchard 1969 [1940]: 11 ).

Sharon Hutchinson não é uma antropóloga pós-moderna no sentido estrito do termo. Além de manter uma linha de continuidade em relação a um dos objetos de estudo mais emblemáticos e "exóticos" do passado da disciplina - os nuer -, não explora etnografias alternativas, nem segue caminhos intelectuais refratários à própria ideia de conhecimento antropológico cumulativo. Em contrapartida, chama a si um dos principais diacríticos da identidade contemporânea quando procede à rejeição da tal ideia de cultura como ilha de consensos e quando, em paralelo, "reivindica seriamente a explicação histórica", em oposição ao presente etnográfico de tipo funcionalista (Hutchinson 1996: 50). Há também uma componente feminista na sua empresa, ao propor-se contrariar a posição "viricêntrica" de Evans-Pritchard e fazer ouvir as mulheres nuer. A obra é representativa do distanciamento da antropologia de hoje em relação a The Nuer e demais monografias da época sobretudo pela preocupação de Sharon Hutchinson face às variações internas da sociedade nuer. Esse posicionamento é indissociável da crescente suscetibilidade dos antropólogos norte-americanos, e não só, em relação às questões de poder, entendido basicamente como manipulação deliberada dos mecanismos de produção e reprodução cultural por parte de certos indivíduos ou grupos dominantes, agindo essencialmente por interesse político ou económico. A par de um decréscimo muito substancial da importância atribuída às estruturas inconscientes da vida coletiva, esta visão hobbesiana das sociedades tem "o seu quê de sombrio", como escreveu Sherry Ortner em tom levemente crítico (1984: 146).

Uma das consequências do chamado power shift, enquanto movimento de vastas dimensões intelectuais que não cabe aqui delimitar (cf. Ortner 2006: 16-17), é a releitura de casos etnográficos outrora classificados como essencialmente igualitários, sendo os nuer um exemplo por excelência de uma sociedade segmentária que, segundo a leitura clássica, não favorecia a constituição e sobretudo a institucionalização de posições de poder. Em Nuer Dilemmas, Hutchinson procura explicitar o que supostamente a separa de Evans-Pritchard: 
“Como é que podemos ultrapassar os modelos estruturais estáticos, assentes em pressupostos de 'ordem', 'circunscrição' e 'homogeneidade' cultural, de forma a apreciarmos a vida social nuer numa matriz mais histórica e dinâmica? [...] Enquanto Evans-Pritchard, como muitos dos seus contemporâneos, estava preocupado nos anos 30 e 40 com questões de 'unidade', ‘equilíbrio' e 'ordem', olhando para a cultura como algo de partilhado e para a etnografia como a compilação desses elementos partilhados, o presente livro concentra-se no desenvolvimento de tópicos de confusão e conflito entre os nuer - e por conseguinte naquilo que não era inteiramente partilhado pelos mesmos. [...] $\mathrm{O}$ que as anteriores gerações de antropólogos tendiam a ver como 'a lógica' de um determinado sistema social tem revelado numa segunda leitura ser apenas a lógica de um dos seus segmentos. Em resultado, as nossas próprias noções de cultura e sociedade têm começado a fraturar-se e a dissolver-se" (Hutchinson 1996: 28).

Esta passagem desperta-nos um primeiro comentário, que se aplica aliás, de modo mais abrangente, à já referida relação de etnicidade entre uma grande parte dos antropólogos de hoje e os de ontem. O contraste posto em evidência por Sharon Hutchinson não só oblitera os importantes estudos de contacto cultural levados a cabo em África desde os anos 20, como deixa de fora os complexos desenvolvimentos teóricos da antropologia social britânica após a Segunda Guerra Mundial. Dessa forma, acentua-se o caráter de novidade das preocupações contemporâneas, quando houve a bem dizer toda uma coorte de antropólogos de renome, discípulos aliás de Malinowski ou de Radcliffe-Brown, que discutiram durante décadas os problemas levantados pelas abordagens mais estáticas. A verdadeira pergunta não é como podemos ultrapassar os modelos estruturais estáticos, já há muito tempo ultrapassados, mas sim como é possível, na viragem do século XXI, apresentar essa preocupação como uma novidade teórica. Evoquemos o caso emblemático de Raymond Firth (1901-2002), uma vez que chamou a si a missão de desfazer, já nos anos 50, aquilo que entendia ser uma visão errada do funcionalismo, inclusive da obra de Radcliffe-Brown, por parte de alguns críticos, como Georges Balandier do outro lado da Mancha, que então vinham propulsionando mais vigorosamente a ideia de dinamismo.

Procurar na vida social uma estrutura, ou seja, identificar um certo número de consensos orientadores do comportamento e das relações entre indivíduos e grupos numa determinada duração histórica, era essencialmente "uma questão de ênfase", ou seja, de ponto de vista (Firth 1964 [1954]: 37). Isto não equivalia a dizer que a vida social se resumisse às suas componentes estruturais, que de resto só podiam ser identificadas por abstração. Embora a estrutura social não fosse uma ilusão desprovida de correspondência empírica, era sem dúvida um instrumento conceptual, tendo em conta que o antropólogo nunca pode 
captar e menos ainda comunicar de forma imediata a realidade. Salvaguardado esse aspeto construído, próprio de uma disciplina com pretensões comparativas, Raymond Firth afirmava que qualquer antropólogo tinha consciência do lado contingente das ações sociais, dos imponderáveis do quotidiano e da história (a não confundir com o simples acaso), e da importância do indivíduo enquanto fator de mudança, mas também como fator de continuidade. Em "Social organization and social change", de 1954, o antropólogo neozelandês afirmava que as escolhas e decisões individuais, tácitas ou manifestas, estavam sempre presentes, quer numa sociedade em profunda transformação, quer numa sociedade com características estruturais essencialmente estáveis. O que devia evitar-se era a tentação de equacionar o livre arbítrio apenas com o conflito, a desobediência, o desvio ou a revolta em relação a uma ordem instituída. O consenso e a aquiescência eram preponderantes em muitos casos, mesmo que de forma inconsciente.

Raymond Firth reconhecia que a linguagem adotada podia sugerir por vezes, de forma errada, uma ideia de intemporalidade que não estava na mente do antropólogo. Também admitia, e era esse o âmago da questão, que o ponto de vista estrutural insinuava amiúde uma escala temporal de continuidade a partir de uma situação observada apenas no presente, por exemplo em relação aos processos de sucessiva segmentação linhageira, sem que tivesse havido uma verdadeira comprovação da efetividade histórica dos mesmos. De qualquer forma, abundavam já os casos em que ocorrera esse tipo de comprovação de continuidades a vários níveis, quer através da utilização de documentos históricos, quer através da revisitação de terrenos por outros antropólogos ou pelo mesmo, como o próprio Firth fez entre os tikopia. Paralelamente, acumulavam-se desde os anos 20 e 30 muitos estudos demonstrativos de acentuadas mudanças em contextos coloniais africanos ou oceânicos, embora com diferentes graus de rotura, de transformação e de continuidade das instituições anteriores (Firth 1964 [1954]: 54-55; cf. Malinowski 1945: 2).

De uma forma ou de outra, e consciente de que muitas pessoas desejavam reduzir a vida social, em todos os contextos imagináveis, a tensões de poder inevitavelmente desintegradoras, Raymond Firth afirmava que não se podia presumir a priori a inexistência de consensos coletivos e de continuidades em torno dos mesmos, ainda para mais quando o veredicto dependia tanto do ponto de vista. Se era absurdo pensar a África negra como parada no tempo antes da Era do Império, igualmente absurdo era pretender que não havia, ou que não pudesse sequer haver, num continente daquelas dimensões, numerosos contextos etnográficos marcados por continuidades profundas, pelo menos nas margens ou no exterior das grandes rotas militares e esclavagistas. Em suma, obrigar toda e qualquer sociedade a ser vista, por preconceito de escola, como uma arena de combate desintegrador, isso sim, era uma atitude anti-histórica e de crença numa lei sociológica fundamental. É tentador, e em nossa opinião 
legítimo, ver aqui uma antecipação de ulteriores tentativas de refreamento dos excessos da antropologia do poder, por exemplo quando Sherry Ortner escreve, em 1984, que é conveniente não exagerar a intencionalidade e atividade dos atores, nem subestimar os casos em que "de facto agem de acordo com as normas simplesmente porque 'os nossos antepassados já faziam assim'” - ou, dito de outra forma, em que a experiência coletiva é inconsciente e mais forte que os indivíduos e segmentos que nela participam. Convém relembrar, sob risco de converter a antropologia numa escola de cinismo e de visões negras, que o ser humano e as suas comunidades também são feitos de solidariedades que não devem ser sistematicamente equiparadas a manobras ideológicas de supostos detentores de poder (Ortner 1984: 150, 157).

No início dos anos 60, Raymond Firth disse que o termo "dinâmico" - presente no discurso antropológico pelo menos desde a década de 1930 - tinha adquirido uma espécie de conotação moral positiva para quem quer que o utilizasse em detrimento das análises de tipo estático, olhadas como conservadoras. Já então muitos antropólogos se estavam a converter em "doutrinários" da maneira certa de ver o mundo (Firth 1964 [1962]: 10). O problema é que essa atitude, em grande medida política, escamoteava as diferenças de ritmo e de tipo de mudança das sociedades humanas, constatadas em diferentes contextos e momentos da história. A crescente preponderância do ponto de vista dinâmico era indissociável das próprias transformações ocorridas em situação colonial, sobretudo no século XX, mas a dimensão histórica da antropologia não podia - ou não devia - limitar-se a essa experiência. Todas as sociedades estavam em permanente fluxo, mas não forçosamente da mesma maneira. Os críticos incorriam sobretudo no erro, ou na injustiça, de tomar à letra o termo "estático", quando nunca ninguém pretendera usá-lo como sinónimo de imobilismo, mas sim de relativa falta de mudança de componentes estruturais. Foi em defesa do patamar de abstração de Radcliffe-Brown, e nomeadamente da sua menção da estrutura como uma rede de relações sociais, que Raymond Firth escreveu as seguintes palavras:

"Ninguém alguma vez pensou que ele acreditasse estar a lidar com um tecido com os seus filamentos e nós ou com um tipo de arranjo cujas linhas de interseção e interstícios fizessem lembrar uma rede em sentido literal. Podemos ter por certo que, ao jeito de um pintor moderno, ele estava apenas a expressar o que sentia, descrevendo metaforicamente aquilo que via" (Firth 1964 [1954]: 36).

É muito significativo que Firth tenha defendido o valor simplesmente metafórico da anódina expressão network, pois dessa forma dava resposta indireta aos detratores de uma outra imagem bem mais polémica, ou seja, a famosa comparação entre uma sociedade e um organismo vivo. O seu colega 
Evans-Pritchard estava aliás no epicentro das vozes críticas desde 1950, afirmando no ensaio "Social anthropology: past and present" que não se tratava apenas de uma questão de palavras, mas de uma visão filosófica efetivamente naturalística, por parte de Radcliffe-Brown. ${ }^{4}$ Entretanto, a partir daquela data - como é sabido, apesar de Sharon Hutchinson não o tomar em linha de conta - Evans-Pritchard defendeu a comunhão entre a antropologia e a história, renegando de vez a imagem das sociedades como sistemas naturais. ${ }^{5}$ Ao fazê-lo, porém, inaugurou em grande estilo a caricatura dos funcionalistas, diabolizando desde logo Malinowski e Radcliffe-Brown como responsáveis pela ilusão de que a dimensão histórica era irrelevante para a compreensão sincrónica das sociedades. Se este tipo de afirmação existiu ao nível do slogan antievolucionista e sobretudo antidifusionista, num período, aliás, em que a academia se viu sob o risco de ser tomada de assalto pela escola heliocêntrica de Grafton Elliot Smith, o facto é que não teve verdadeira correspondência na diversificada prática etnográfica dos britânicos, incluindo o próprio Evans-Pritchard.

Para compreender corretamente o que foi o funcionalismo britânico, não basta esbarrar no desejo manifestado por Radcliffe-Brown de encontrar leis sociológicas; como não basta ler a introdução de African Political Systems, de 1940. Ao contrário dos preconceitos que traga, o leitor desta obra coletiva está constantemente a deparar-se com a história e o contexto colonial (cf. Vincent 1990: 259). A etiqueta funcionalista não faz mais, aliás, do que induzir em erro quando aplicada de forma redutora e esquematizadora, mais valendo quiçá abandoná-la. Já naquele tempo a antropologia social britânica conjugava sensibilidades muito diversas, sendo necessário assimilar bastantes mais autores do que Meyer Fortes ou Evans-Pritchard para não incorrer em grosseiras desvirtuações de toda uma era intelectual - durante a qual, aliás, nunca ninguém pretendeu ter descoberto uma lei sociológica em sentido literal. É interessante, a propósito, citar estas palavras retrospetivas de Godfrey Lienhardt acerca da sua geração oxoniana: "Cada um de nós seguia o seu caminho sem a mais leve sensação de haver uma ortodoxia reinante, e possivelmente andávamos uns e outros a ensinar segundo princípios contraditórios" (Lienhardt 1974: 300). De resto, foi há já perto de meio século atrás que Isaac Schapera demonstrou o aspeto inteiramente deturpador das críticas dirigidas em bloco aos "funcionalistas" por alegadamente fazerem abstração da história, num

4 Veja-se, a este propósito, o recente artigo de Tim Ingold escrito “em defesa de Radcliffe-Brown”, no qual procura demonstrar que Evans-Pritchard desvirtuou o pensamento do mestre (Ingold 2008).

5 O texto mais emblemático da "viragem" de Evans-Pritchard para a história é Anthropology and History, de 1961, mas os argumentos aí avançados reproduziam no essencial a sua Marett Lecture de 1950 ,

"Social anthropology: past and present". 
artigo intitulado "Should anthropologists be historians?" (Schapera 1962; cf. Firth 1951).

No fundo, o que distinguia uma análise estática de uma análise dinâmica não era forçosamente a sincronia versus a diacronia, ou o presente etnográfico versus a história, mas sim o tipo de mudança captado pelo observador. Uma análise estática, como a de Meyer Fortes entre os tallensi, contemplava os movimentos não desintegradores ou pouco desintegradores dos consensos sociais e culturais vigentes, inclusive em torno da violência, deixando a porta aberta para quem os quisesse tratar do ponto de vista dos acontecimentos históricos. Max Gluckman desenvolveria a ideia de que as perturbações eram inerentes à própria noção de equilíbrio, mas a ideia não era nova: "As sociedades africanas não são modelos de harmonia interna contínua" (Fortes e Evans-Pritchard 1983 [1940]: 51). Uma análise dinâmica, em contrapartida, procurava as forças ativas, subterrâneas ou não, que estivessem a operar mudanças mais profundas, conducentes a uma nova realidade social ou cultural. Nada obstava, como é óbvio, a que um mesmo estudo combinasse os dois tipos de enfoque, em função do contexto histórico. Para além disso, dificilmente um estudo dinâmico podia lidar apenas com fenómenos de transformação e excluir a priori que estes se pudessem articular com aspetos de profunda permanência cultural, dependendo também, claro está, da sensibilidade do observador.

Por muito que já se tenha escrito sobre esta matéria, é sempre conveniente relembrar que a palavra história, só por si, não esclarece nada, pois que se presta a sentidos diversos e até contraditórios. Por exemplo, um estudo de contacto cultural na África dos anos 30 pode ser considerado histórico por lidar com questões de mudança e ao mesmo tempo a-histórico por não reconstituir o passado tribal pré-colonial. Ora, o mesmo pode ser dito acerca deste tipo de reconstituição, invertendo os pólos da argumentação - como tem sido mais frequente nas críticas pós-modernas. Malinowski nunca deixou de considerar legítima e premente a reconstituição do passado pré-colonial recente, especialmente quando estava ainda bem presente na memória e na própria vivência atuais, o que emprestava maior rigor metodológico à empresa. O que mudou no seu discurso foi o reconhecimento explícito de que isso era fazer história. Mas havia outro sentido mais profundo segundo o qual a descrição funcionalista da sociedade nativa era intrinsecamente histórica: "O contexto temporal e o contexto cultural, essenciais para a abordagem funcionalista, são conceitos históricos" (Malinowski 1945: 34).

Talvez nenhum caso corresponda melhor à ideia de que as análises estáticas tinham uma dimensão diacrónica do que justamente The Nuer, precisamente pela interpretação do conflito como princípio estruturante das relações sociais, não só entre nuer, mas com os vizinhos nilóticos. O que se pretende afirmar com isto é que a estática de Evans-Pritchard, mesmo sendo de tipo funcionalista, não exclui a história e representa à sua maneira uma visão histórica, 
pois que constrói as suas próprias conclusões relativamente a uma certa continuidade cultural no passado. Para as rejeitar, não basta evocar um dogma de sociologia do poder; é necessário substituí-las, através de um estudo histórico aprofundado do contexto etnográfico em questão, por uma identificação concreta de mudanças (ou de fatores de mudança) estruturais, e não apenas de caráter événementiel. Para além disso, a sua obra-prima tinha uma componente dinâmica não negligenciável, pois considerava que o aparecimento dos homens do Norte, primeiro os árabes do Sudão e depois os britânicos, tinha espoletado um tipo de solidariedade que anteriormente não existia, ou seja, entre tribos nuer, em torno da figura dos profetas.

\section{SHARON HUTCHINSON NA PEUGADA DE PAUL PHILIP HOWELL}

Os nuer e Evans-Pritchard são praticamente sinónimos na mitologia da disciplina, mas não é possível, na abordagem da problemática crucial dos consensos e das continuidades sociais e culturais, contornar o facto de que não foi ele o primeiro nem o último a apresentá-los ao mundo. Pelo contrário, foram descritos por numerosos visitantes e agentes na região, antes (desde 1839), depois e também no mesmo período. Os críticos da autoridade etnográfica de Evans-Pritchard deveriam sem dúvida ser os primeiros a proceder a uma comparação sistemática dos conteúdos dos diferentes registos da sociedade nuer. Esse trabalho a que se escusam é afinal bem mais árduo antropologicamente e, diga-se de passagem, traz resultados pouco convenientes para o objetivo que desejam alcançar. No seu ensaio "On ethnographic authority”, James Clifford reconhece todavia com alguma humildade que a sua focalização na observação participante como "núcleo da etnografia do século XX" descura outras formas de autoridade, nomeadamente "o peso do conhecimento acumulado" em arquivo, "acerca de grupos específicos" (Clifford 1983: 142).

Destacaremos aqui o administrador colonial Paul Philip Howell (1917-1994), que entrou em cena como district commissioner nos anos 40 e permaneceu no Sul do Sudão até à independência. Howell antecipou as críticas que podiam recair sobre uma investigação etnográfica levada a cabo por um administrador colonial, como se não fosse suficiente garantia intelectual o seu doutoramento em antropologia pela Universidade de Oxford após a Segunda Guerra Mundial. O facto de se encontrar numa inequívoca posição de poder face aos nuer podia "desencorajar respostas sinceras e verdadeiras" às suas perguntas. Ora, essa desvantagem era mais imaginária do que real no seu entender, se não mesmo fruto de preconceitos ideológicos. Com efeito, qualquer pessoa conhecedora do contexto sudanês nos anos 40 e 50 poderia atestar "a relação de intimidade que existe entre os nuer e os seus district commissioners, tão estreita que chega ser verdadeiramente esgotante". Feitas as contas, as vantagens do ponto de vista antropológico eram muito mais que as desvantagens. 
Howell não era um mero observador participante, mas um ator integrado na realidade social nativa. A sua etnografia derivava aliás de uma "rigorosa análise de milhares de casos concretos" (Howell 1954: 3, 4).

As circunstâncias no terreno tinham mudado bastante, sem dúvida, desde a repressão militar dos profetas nuer e seus seguidores no final dos anos 20 . Abstendo-se de qualquer juízo moral sobre esse assunto, Howell limitava-se a sublinhar que os administradores coloniais tinham desde então desenvolvido um intenso trabalho para que os nuer aceitassem melhor a dominação britânica e ultrapassassem o ressentimento de povo ferido no seu orgulho guerreiro. No dizer do autor, a desconfiança estava "erradicada" do território pelo menos desde os anos 40 e os nuer tinham-se tornado "essencialmente amigáveis" em relação aos britânicos (Howell 1954: 15). Este cenário de "apaziguamento", como the chamou, contrastava com o encontrado por Evans-Pritchard em pleno rescaldo do "Nuer Settlement", a referida campanha de repressão militar, ocorrida no ano anterior ao da sua chegada em 1930. O paulatino aperfeiçoamento dos tribunais nativos contribuiu bastante para tal. A transformação do costume em lei foi um processo de colaboração anglo-nuer que teve o seu ponto culminante na publicação, em 1954, do livro de Howell A Manual of Nuer Law. Com efeito, os tribunais nativos instituídos pelo governo procuravam respeitar o mais possível os costumes nuer e especialmente a linguagem das compensações em gado. De outra forma, dizia Howell, os nuer simplesmente não se submeteriam à lei.

Havia contudo alterações sociais significativas relacionadas com o próprio aspeto coercivo das deliberações judiciais. É curioso notar que essa componente inovadora da obra de Howell, com recurso a constantes comparações entre o passado e o presente, foi desperdiçada pelos participantes do grande fórum teórico dos anos 60, 70 e 80 . Howell era citado com frequência, mas apenas pela sua etnografia das instituições tradicionais. Esta constatação é tanto mais contraditória quanto a "Nuer industry" ${ }^{6}$ foi contemporânea de intensos debates em torno do colonialismo, dentro da nova atmosfera política da antropologia. Seria preciso esperar pela entrada em cena de Sharon Hutchinson para que o conteúdo dinâmico do Manual of Nuer Law fosse devidamente valorizado. O livro de Paul Philip Howell surgiu então a seus olhos como um missing link, um complemento precioso do seu trabalho de campo, a par da consulta dos arquivos oficiais do período colonial. Em Nuer Dilemmas, Hutchinson valoriza o Manual of Nuer Law como uma obra "diretamente incrustrada em questões de mudança histórica e, em particular, no impacte do domínio colonial sobre as práticas tradicionais de casamento, divórcio, herança, homicídio, adultério, posse de gado, compensação de sangue, etc." (Hutchinson 1996: 21, 32, 43). 
Este apreço por Howell ocorre em detrimento de Evans-Pritchard, ou pelo menos através de uma discutível acentuação das diferenças entre os dois. Em contraste com o administrador colonial, o antropólogo teria cometido o pecado de ignorar ou, melhor dizendo, de só fazer breves referências à interferência dos britânicos na vida social dos nuer, referências essas que de qualquer forma tendiam a perder-se no cômputo geral da sua antropologia "intemporal" ou de "amnésia histórica". Pela nossa parte, não partilhamos de todo esse juízo acerca de um homem que não só se recusou a entrevistar os profetas nuer que então se encontravam na prisão, ainda no rescaldo do "Nuer Settlement", como deixou impressa, de forma ostensiva para o contexto da época, essa recusa; e que, para além disso, considerava que essas figuras-chave tinham tentado criar um novo patamar de aglutinação tribal em reação à presença colonial.

Sharon Hutchinson vai mais longe e afirma que a organização social nuer tal como foi descrita por Evans-Pritchard era "uma ilusão provocada pelas teorias dominantes que guiavam a investigação antropológica naquele tempo" (Hutchinson 1996: 30, 31). Por estranho que possa parecer, Nuer Dilemmas é uma obra que veicula constantemente a ideia contraditória de que a oposição segmentária, com todas as instituições culturais a ela associadas, foi uma realidade no passado. Para já, interessa-nos repor alguma justiça na avaliação das relações intelectuais entre Howell e Evans-Pritchard. No seu prefácio ao Manual of Nuer Law, este último dava grande importância ao facto de se tratar de uma descrição das mudanças ocorridas por efeito de uma "autoridade exterior", de um "governo vindo de fora", desde o tempo do seu próprio trabalho de campo vinte e cinco anos antes (Evans-Pritchard 1954: vi).

Convenhamos que Evans-Pritchard tinha uma clara noção de que os nuer haviam sido "o último povo importante a ser subjugado" (Evans-Pritchard 1969 [1940]: 134). Estava aliás convencido de que em 1930 ainda se conservavam basicamente como eram antes da chegada dos britânicos, não tendo tido sequer tempo para sofrer grandes mudanças culturais e sociais. Esta perspetiva tinha também a ver com a convicção de que as razias esclavagistas dos árabes junto de algumas comunidades ribeirinhas tinham sido, de facto, muito periféricas, justamente por questões de natureza geográfica e ecológica, relacionadas com a dificuldade de penetração no vasto e semipantanoso território nuer. Deve notar-se que este ponto de vista não significa uma negação da história, mas uma visão concreta dos acontecimentos no Sul do Sudão no século XIX. De resto, nos anos 30 ninguém tinha muitas dúvidas de que o contexto dos povos nilóticos, em comparação com o das populações destribalizadas, proletarizadas e flutuantes das colónias do Sul de África, era um verdadeiro bastião de cultura nativa.

Mais ainda, o que se passou naquele cenário nilótico, segundo Evans-Pritchard, não foi uma simples existência de "unidade, equilíbrio e ordem", como sugere Hutchinson, mas sim de continuidade estrutural de sangrentos 
conflitos internos e de violentíssimos raides de captura de gado, mulheres e crianças dinka ou de outros grupos vizinhos. Nada podia estar mais longe da verdade do que a colagem do nome de Evans-Pritchard à alegada noção clássica da cultura como uma ilha isolada - logo ele, que tão clara perceção tinha da relação visceral entre nuer e dinka, refletida na própria composição das aldeias nuer por uma larga percentagem, por vezes na ordem dos 60\%, de indivíduos de origem dinka, capturados ou descendentes de capturados! Aliás, na sua trilogia, vários tópicos capitais da sociedade e da religião eram atribuídos a desenvolvimentos históricos oitocentistas, nomeadamente o apogeu da expansão militar nuer para leste em meados do século, conducente a uma agudização dos processos de interpenetração cultural entre nuer e dinka. Evans-Pritchard ia ao ponto de afirmar que a estrutura política dos nuer "só pode ser compreendida através da relação que mantêm com os vizinhos" (1969 [1940]: 125). A bem dizer, The Nuer poderia ser lido, hoje, como um clássico da problemática da etnicidade, onde se encontram alguns ingredientes prediletos, como a extrema parecença cultural entre nuer e dinka e, mais do que parecença, origem comum reconhecida no mito por uns e outros, a par da impossibilidade de se definirem sem ser através dessa relação de oposição e de alguns casos conhecidos de mudança de identidade étnica (de dinka para nuer) por parte de homens adultos. Aliás, o tema das relações pré-coloniais entre nuer e dinka já foi tratado e acesamente debatido nesse âmbito nos anos 70, por figuras como Peter Newcomer, B.H. MacDermott e Aidan Southall, não havendo muitas dúvidas, nessa altura, de que Evans-Pritchard tinha ido muito longe no reconhecimento da relação intrincadíssima entre nuer e dinka (Southall 1976: 463).

O modelo da oposição segmentária foi construído com um vocabulário geométrico, e até mesmo com figuras geométricas, nalgumas passagens. Esse pode ser o patamar mais emblemático da obra, mas não é o único. É conveniente que os leitores de The Nuer não se esqueçam em simultâneo de visualizar o que é, empiricamente falando, um blood feud ou um raide levado a cabo por mancebos que cresceram como guerreiros. A identificação que Evans-Pritchard fazia do combate como "valor cardinal" dos nuer transcendia em vários momentos aquele nível de abstração e descia dos segmentos até às pessoas envolvidas nas ocorrências sangrentas e na sua resolução. $\mathrm{O}$ turbilhão histórico dos violentos conflitos internos e externos em que a sociedade nuer estava mergulhada de forma crónica - ou, melhor dizendo, estrutural -, conferia aliás amplo espaço para a ação individual na ausência de lideranças políticas institucionalizadas.

Em suma, a incipiência da administração colonial nas primeiras décadas do séc. XX e as tremendas dificuldades em lidar com os nuer justificavam largamente, no entender de Evans-Pritchard, um enfoque nas instituições tradicionais. Apesar dessa incipiência - ou por causa dela - é que os profetas tinham estado no epicentro da resistência aos britânicos. Evans-Pritchard 
reconheceu-os como líderes da revolta, sendo até, por esse motivo, alvo das críticas de Douglas H. Johnson, o historiador dos nuer, que (discutivelmente) reivindica para esses personagens um estatuto pacifista, na sua obra de 1994, The Nuer Prophets. Para usar uma expressão coloquial, Evans-Pritchard é preso por ter cão e preso por não ter, quando na realidade acolheu com grande entusiasmo a atualização histórica proporcionada pela obra de P.P. Howell.

Sharon Hutchinson também acentua o contraste entre os dois autores no que diz respeito à homogeneidade cultural dos nuer. Evans-Pritchard teria procedido a uma generalização abusiva, subestimando as disparidades de ideias ou de práticas e as variações regionais, enquanto Howell se teria revelado "especialmente atento" às mesmas (Hutchinson 1996: 43). Ora, este juízo oblitera o facto de que Howell procedia a uma confirmação plena de praticamente tudo o que fora dito por Evans-Pritchard, "com exceção", no dizer do próprio, "de pequenas variações locais sem grande importância no quadro geral” (Howell 1954: 16). Ou seja, Howell não considerava que as variações regionais ou outras fossem de molde a impedir uma caracterização global dos nuer, basicamente porque eram variações dentro de um tema. Aos leitores surpreendidos com o aspeto repetitivo de uma obra em relação à outra, Howell fazia questão de dizer que o seu trabalho de campo fora levado a cabo com total independência e essencialmente noutras tribos nuer. Esta corroboração é porventura a mais significativa no cômputo geral do arquivo nuer, dada a elevada competência técnica de Howell, só que ninguém, tanto quanto sabemos, ainda a tomou seriamente em linha de conta. O certo é que Evans-Pritchard não deixou de se regozijar com uma tal concordância, chegando mesmo a dizer que "os valores fundamentais de uma sociedade podem por vezes ser vistos com mais clareza quando a mesma está em processo de reajustamento a novas circunstâncias históricas" (Evans-Pritchard 1954: vi; o itálico é meu). Estamos portanto perante um caso de fusão entre uma abordagem dinâmica das transformações em contexto colonial e uma perceção inequívoca da permanência de vetores culturais antigos.

Para Sharon Hutchinson, no entanto, quaisquer diferenças de opinião e ação são demonstrativas da "falta de consenso" entre os nuer, o que constitui o leitmotiv da sua obra, expresso nos "dilemas" do título (Hutchinson 1996: 34). Ao chegar ao Sul do Sudão no final dos anos 70, ficou espantada com as encaloradas discussões acerca da eficácia ou inutilidade de algumas instituições supostamente basilares, como o sacrifício, a iniciação dos rapazes ou o estado de impureza momentânea de quem derramava sangue da mesma tribo. Para além disso, desenvolveu o seu trabalho de campo em comunidades distanciadas, o que lhe permitiu constatar que os nuer ocidentais eram mais refratários a inovações e os orientais mais abertos, até pelos diferentes percursos históricos de uns e outros. Mesmo admitindo que as generalizações de Evans-Pritchard pudessem ter sido uma realidade em tempos idos, a antropóloga americana 
recusa-se a fazê-las no presente, ao ponto de afirmar que lhe seria extremamente penoso discorrer sobre "os nuer" ou "a cultura nuer" (Hutchinson 1996: 37, 38). E a verdade é que, em relação ao passado, também acaba por usar o mesmo tipo de discurso, lançando sobre Evans-Pritchard as seguintes suspeitas:

“[...] não pude deixar de me interrogar se no tempo do trabalho de campo de Evans-Pritchard não haveria uma variabilidade cultural e tensões sociais como as que verifiquei serem um aspeto tão marcante da vida social nuer contemporânea. Não poderiam simplesmente ter escapado ao seu olhar? Talvez se the tenham deparado controvérsias de relevo e mesmo assim as descartasse do objetivo principal da sua investigação, isto é, a construção de um modelo pré-colonial da sociedade nuer" (Hutchinson 1996: 34).

Na verdade, não existem grandes indícios de que houvesse então acesas discussões, comparáveis às da atualidade, sobre temas capitais da existência nuer tradicional. Pelo contrário, é possível extrair várias conclusões de concordância - desde logo concordância em relação aos modos do conflito - a partir dos conteúdos acumulados, desde 1839, no arquivo etnográfico nuer. Esse facto é reconhecido aliás pelo historiador Douglas $\mathrm{H}$. Johnson em diversas passagens da sua obra, apesar não ser esse o seu interesse, nem o seu ponto de vista. Sharon Hutchinson inclina-se todavia para pensar que os antropólogos de hoje são capazes de ver coisas que os de ontem não detetavam ou a que pelo menos não atribuíam importância, quer em relação ao passado pré-colonial e colonial, quer em relação ao presente.

O facto é que a sua rejeição da ideia de "cultura nuer" é ditada em grande medida pela academia, ou seja, pelo ponto de vista hegemónico. Não pretendemos de forma alguma negar a evidência, ou seja, que o terreno de Hutchinson tem a marca de múltiplas transformações, algumas bastante profundas, ocorridas no período colonial e pós-colonial. Consideramos precisamente, bem pelo contrário, que o contexto nuer da atualidade tem muito mais variações sociais internas do que no passado, tendo em conta por exemplo o crescente número de cristãos, a própria diáspora dos exilados da guerra civil, bem como a consolidação de uma faixa urbana in loco, e até mesmo o acesso de uma minoria nuer ao ensino universitário, sendo que Sharon Hutchinson trabalhou sobretudo entre as comunidades rurais. O que dizemos é que a antropóloga, para se distanciar do passado da disciplina, desvaloriza teoricamente as diferenças flagrantes no grau de variação interna dos nuer do tempo de Evans-Pritchard e do seu tempo. Paralelamente, o enfoque sistemático nas variações da atualidade escamoteia o facto, também ele bastante evidente, de que as mesmas confirmam os consensos herdados do passado. Novas condições sociais e materiais, representadas pelo dinheiro de papel ou pela introdução de armas de fogo, 
impõem forçosamente a discussão consciente de como adaptar e reinterpretar aquelas instituições e representações coletivas.

Pretender que nunca tenham existido, entre os nuer ou em qualquer outra sociedade sem escrita, os consensos que foram vislumbrados e valorizados pelos antropólogos modernos em relação a um tempo de reprodução social considerada relativamente mais estática e mais tácita parece-nos uma atitude dogmática, de resto bastas vezes desmentida pelo arquivo secular da história da antropologia. Aliás, Sharon Hutchinson faz bem em frisar as mudanças de estilo da disciplina, pois de certa forma é no patamar da retórica que a sua obra minimiza a partilha de valores entre os nuer, tanto no presente como no passado. Por exemplo, a sua etnografia demonstra sem margem para dúvidas que os bois continuam a ser "a metáfora dominante do valor das coisas" (Hutchinson 1996: 50). Além de implicar uma visão homogénea da ideologia do gado antes do impacte colonial, essa constatação traduz-se em algumas generalizações inequívocas sobre a realidade atual. Apesar da cómoda interferência do dinheiro, nomeadamente em transações distanciadas do parentesco e da religião, o gado é idealmente utilizado nas ocasiões mais importantes, como o casamento, a iniciação ou o sacrifício. "Para sumarizar as declarações dos nuer a este respeito", escreve Hutchinson, "eu diria que o gado é reservado para a criação e afirmação de laços perenes entre os homens ou entre os homens e a divindade" (Hutchinson 1996: 73). Numa palavra, a fórmula "o dinheiro não tem sangue" preserva a função simbólica dos animais. Ora, logo depois de uma conclusão tão ambiciosa sobre a permanência de um dos traços capitais da cultura nuer desde que há memória, a autora apressa-se a atenuá-la: "Isto não quer dizer que os homens e as mulheres nuer dos anos 80 tenham chegado a um estado de consenso [...]” (Hutchinson 1996: 98).

$\mathrm{Na}$ sua recusa das noções holistas de cultura, a antropóloga norte-americana explora até à exaustão a atual "falta de consenso" dos nuer sobre questões como a diferença entre a morte por arma de fogo e a morte por lança, quando esta discussão é só por si representativa de outros consensos mais fundos. É também por fugir a uma visão do todo que discorre longamente sobre o significado não militar (sic) das armas de fogo - aliás, somente entre os jikany orientais, pois a ocidente as lanças ainda eram dominantes aquando do seu trabalho de campo. Por "significado não militar", a autora entende o efeito sedutor das espingardas no sentido literal do termo, estando associadas aos conceitos locais de "potência masculina, beleza e força" (Hutchinson 1996: 150). Como dissemos atrás, um dos objetivos deliberados de Hutchinson consiste em contrariar a posição "viricêntrica" de Evans-Pritchard e dar voz ao elemento feminino, mas na verdade a sua etnografia revela uma profunda coincidência ideológica entre homens e mulheres no que respeita a múltiplos temas-chave da vivência nuer, a começar pela valorização entusiástica e voluntariosa, por parte das mulheres, da combatividade guerreira e da simbologia 
masculina das armas, ao ponto de algumas se vangloriarem de terem empurrado os seus homens para a guerra com o Norte, envergonhando-os através de comparações femininas (Hutchinson 1996: 134, 150-153). É aliás bastante óbvio, em nosso entender, que essa associação simbólica de natureza sexual tem implicações militares das mais profundas.

Quando são deixadas de lado as preocupações de explícita conformidade com o discurso dominante na cena antropológica norte-americana, os consensos culturais emergem ao longo de Nuer Dilemmas, sobretudo no que respeita às instituições tradicionais tais como Evans-Pritchard e Howell as descreveram. Este último concordava - e Sharon Hutchinson também concorda - que a resolução de conflitos internos, nomeadamente blood feuds, nunca era um dado adquirido no cenário pré-colonial. O kuaar muon só funcionava como árbitro se os grupos em litígio entendessem escutá-lo, não tendo portanto autoridade para impor uma decisão. Mesmo quando a compensação em gado era aceite pelos parentes da vítima, geralmente sob pressão da comunidade reunida em torno do sacerdote, nada assegurava o termo definitivo das hostilidades, podendo haver retaliações súbitas perpetradas por elementos de sangue mais quente, sobretudo jovens adultos. Eram frequentes os reacendimentos da violência durante e depois do arrastado processo de pagamento, numa sucessão de vinganças mútuas indissociáveis da oposição segmentária. Esquecendo que o modelo funcionalista "não passava de uma ilusão", Sharon Hutchinson veicula as ideias-chave de Evans-Pritchard e de Howell sobre a maquinaria tradicional dos conflitos, afirmando que eram tão mais difíceis de resolver quanto maior fosse a distância entre as partes (Hutchinson 1996: 122-124).

Contrariar esse estado de coisas foi um dos principais objetivos da consolidação dos tribunais nativos por parte dos britânicos. Tal como Evans-Pritchard, Howell sublinhava que só as características pessoais podiam colocar qualquer nuer numa posição de certa proeminência política, pelo que a rede de "chefes tribais" com poderes e insígnias atribuídos pelo governo foi constituída através da identificação desses homens. Sharon Hutchinson segue Howell de muito perto no que se refere às consequências sociológicas da nova instituição. Segundo o administrador colonial e antropólogo, a autoridade conferida aos presidentes dos tribunais - chamados kuaar book pelos próprios nuer, por terem um livro como sinal distintivo - acarretava alterações substanciais na dinâmica da oposição segmentária, já que a sua missão principal consistia precisamente em contrariar os blood feuds entre segmentos tribais. Os tribunais nativos tinham a obrigação de garantir que as indemnizações em gado seriam não apenas aceites por ambas as partes, mas cumpridas no imediato. Howell punha em evidência que "o homicídio e a retaliação violenta foram as primeiras características da sociedade nuer a receber a atenção da administração" no período subsequente ao "Nuer Settlement" (Howell 1954: 60). Face à elevada incidência de homicídios, os britânicos encontraram uma solução híbrida que 
lhes permitiu introduzir o conceito de responsabilidade criminal individual, desconhecido dos nuer. Não só fixaram em cinquenta o número de cabeças de gado devido em compensação automática, o que na prática correspondia a uma inflação da responsabilização coletiva, como introduziram em complemento a pena de prisão, que inicialmente gerava grande confusão nos espíritos.

Note-se que o reacendimento de conflitos ainda era uma realidade nos anos 50 , tendo portanto atravessado todo o período colonial. Howell não tinha pejo em reforçar a ideia de Evans-Pritchard de que a oposição estrutural entre segmentos tinha expressão empírica na violência física. Devido à sua passagem pela academia, estava bem consciente de que alguns antropólogos - e referia-se com certeza a Max Gluckman - tendiam a ver os conflitos, sobretudo os de proximidade, como uma "expressão meramente convencional daquela oposição” (Howell 1954: 39). Apressava-se pois a pôr os pontos nos ii, não pelo gosto de "exagerar a incidência das lutas entre os nuer", mas porque de facto os combates também eram frequentes nos graus inferiores da pirâmide tribal. Seria um erro pensar que os nuer não davam uso às lanças e mocas "que conservam sempre junto de si”. Não era por acaso que a maioria dos homens tinha o corpo coberto de cicatrizes. É certo que as demonstrações de força em larga escala, nomeadamente as intertribais, estavam praticamente extintas desde o "Nuer Settlement". Muito em especial os raides contra os dinka ou os anuak permaneciam sob ameaça militar do governo. Contudo, Howell tinha conhecimento de formas de agressão ainda vigentes entre segmentos nuer. Em suma, as retaliações paralelas à justiça dos tribunais nativos não estavam inteiramente erradicadas e só a pouco e pouco se poderia consolidar uma opinião pública "consciente de que o derramamento de sangue é uma ação moralmente condenável” (1954: 39).

De qualquer forma, a repressão judicial da violência estava a dar resultados. Os novos métodos de punição imediata conduziram a uma redução efetiva do número de homicídios e por conseguinte os blood feuds também estavam a diminuir. Em contrapartida, era de temer que a organização social tradicional estivesse a desintegrar-se por causa disso. Longe de considerar que o combate era o "passatempo nacional dos nuer", Howell estava convencido da importância estrutural do conflito nos movimentos de equilíbrio da oposição segmentária, em acordo com a visão de Evans-Pritchard. Constatava então uma tendência crescrente para a fissão em segmentos menores, que tinham cada vez mais dificuldade em atingir níveis de solidariedade mais alargados. Os tribunais nativos corriam o risco de se tornarem os únicos mecanismos de controlo social, quando eram justamente os responsáveis pela crescente compartimentação das litigações. De resto, o patamar segmentário dos próprios tribunais foi-se tornando cada vez mais baixo, com pequenas comunidades a exigirem o seu próprio kuaar book em vez de integrarem uma instância superior. Howell suspeitava que os nuer estivessem a fechar-se cada vez mais nos 
laços de solidariedade imediatos. Esta leitura não podia ser mais funcionalista e foi uma das respostas dadas, com quarenta anos de antecedência, à questão colocada por Sharon Hutchinson em 1996: como podemos ultrapassar os modelos estruturais estáticos? Howell não é propriamente um achado inaudito e isolado, mas um representante de pleno direito das transformações precoces, variações internas e sucessivas adaptações da antropologia social britânica. Porventura pouco ciente desta nuance e das incongruências que isso levanta, Sharon Hutchinson integra as ideias de Howell no quadro de novidade da sua própria "etnografia histórica", afirmando que as alianças políticas mais alargadas foram dificultadas - "undermined" - pelos novos mecanismos de repressão dos conflitos (Hutchinson 1996: 119, 130).

O governo britânico devia estar atento a essa deriva potencialmente caótica, dizia Howell. Mas eram palavras com os dias contados. A independência do Sudão, declarada unilateralmente pelos árabes do Norte em 1955, teve consequências fatais para o Sul. É pelo menos esta a ideia de Sharon Hutchinson, pois entende que a administração colonial não preparou o futuro dos tribunais nativos e por conseguinte deixou os nuer com muito frágeis instituições de controlo dos blood feuds. A violência interna rebentou como uma panela de pressão: “Todas as regiões nuer experimentaram uma forte escalada na virulência dos conflitos entre comunidades a seguir à abrupta partida dos britânicos em 1955-56. Muitas pessoas tomaram isso como uma oportunidade para ajustar velhas contas pela força das armas" (Hutchinson 1996: 110, 133). Poderíamos depreender que o problema foi acentuado pela fragilização da solidariedade segmentária ocorrida durante a vigência da "Indirect Rule", só que a autora não esclarece esse ponto. Sabemos que os conflitos internos posteriores à independência se passam entre "comunidades", mas não mais do que isso, talvez por aversão à simetria conceptual do vocabulário político criado expressamente por Evans-Pritchard. Para todo o período que vai do final dos anos 50 até à atualidade, a expressão utilizada é sempre "intercommunity fighting" ou "intercommunity feuding", sem qualquer explicação adicional. Muitas questões ficam por responder ao nível das alterações da organização social, mas uma coisa é certa: não é possível ler Nuer Dilemmas sem sermos assombrados por fantasmas da história da antropologia.

Os nuer são hoje uma "etnicidade militarizada", sujeita a uma teia de forças políticas e económicas exteriores ao contexto nilótico e ao próprio Sudão (cf Hutchinson 2000). Não se deve evidentemente buscar explicações simplistas para uma guerra cuja complexidade extravasa ao mesmo tempo as competências da antropologia e a compreensão do comum dos guerreiros. Ora, neste último plano mais terra a terra do conflito, o ethos de combatividade pode, em si mesmo, ser um fator crucial a ter em conta. De resto, passaram vários anos até os nuer se compenetrarem de que o seu principal inimigo era o exército do novo governo sudanês, e mesmo depois disso continuaram 
a matar-se entre si com inusitada frequência, sem esquecer o ressurgimento dos conflitos interétnicos com os dinka e demais povos nilóticos - um assunto não abordado na monografia, mas de trágica atualidade ainda hoje. É com um sentimento indisfarçavelmente dilacerado que Sharon Hutchinson cita as orgulhosas afirmações de alguns dos seus interlocutores nuer no próprio momento em que estavam a mergulhar na segunda guerra civil com o Norte: "Nós, nuer, não sabemos nada de política. Aquilo de que sabemos é a guerra. É esse o maior bem dos nossos corações. A guerra! Nós não tememos a morte, e até as nossas mulheres são corajosas" (Hutchinson 1996: 105).

\section{CONCLUSÃO}

Sob a inspiração de Regna Darnell, propusémo-nos procurar genealogias invisíveis entre a produção contemporânea e os funcionalistas britânicos, em particular Evans-Pritchard. Através de um estudo de caso, procedemos a um esbatimento de certas oposições entre o presente e o passado da antropologia, admitindo que em grande medida são hipérboles. Constatámos, por um lado, que as noções ditas clássicas podem perpassar de forma subterrânea o discurso daqueles que dizem rejeitá-las. Assim acontece na obra selecionada de Sharon Hutchinson, Nuer Dilemmas, de 1996. É a propósito dos padrões pré-coloniais que mais se evidencia a aceitação implícita da etnografia de Evans-Pritchard por parte da antropóloga norte-americana, inclusive dos mecanismos da oposição segmentária, todavia relegados, no plano do discurso, à categoria de mera ilusão funcionalista. Já em relação ao trabalho de campo de Hutchinson, chega a ser espantoso como um povo dilacerado por décadas de guerra civil em várias frentes conserva tantos traços culturais do passado, desenvolvendo elaboradas soluções de salvaguarda da equação fundamental entre o homem e o gado. Porque tem uma perspetiva da história focalizada nas mudanças em detrimento das permanências, e nas diferenças em detrimento das similitudes, Hutchinson recusa qualquer generalização ou abstração, mas o facto é que podemos detetar na sua monografia várias situações de consenso e perenidade cultural entre os nuer, passíveis de serem valorizadas a partir de outro ponto de vista, complementar em relação ao primeiro.

A antropologia contemporânea é sem dúvida pautada por uma rejeição de todas as formas de "reificação" da cultura como algo de detetável numa diacronia profunda. O facto é que a ideia de continuidade não tem por que ser confundida com a de reprodução estática. Já nos anos 30 Malinowski chamava a atenção para a necessidade de identificar as razões por que determinadas instituições sobreviviam às mudanças ocorridas em contexto colonial e se adaptavam ao mesmo com maior ou menor alteração. Não acreditava que o conservadorismo seletivo fosse mera obstinação, mas sempre uma resposta ao próprio dinamismo das novas condições. Ora, isto não significa que não haja 
genealogias culturais identificáveis entre o passado e o presente, demonstrativas da durabilidade de certas instituições, ainda que sujeitas a transformações históricas. Também é evidente que a subjetividade da leitura será tanto maior quanto mais estiverem em causa valores e dimensões espirituais; mas tal não basta para eliminar da antropologia esse tipo de ambição ou de hipótese.

Por outro lado, muitas das preocupações atuais já tinham expressão nas etnografias ditas modernas, sendo até salutar repor algum presentismo na apreciação das mesmas. Assim, frisámos não apenas que as abordagens estáticas tinham uma componente histórica, mas também que a antropologia social britânica teve as suas próprias respostas teóricas e metodológicas para as transformações sob domínio colonial. No caso dos nuer, independentemente de Evans-Pritchard já ter explorado esses caminhos, sobretudo no capítulo dos profetas como líderes de resistência, coube a Paul Philip Howell detetar as consequências diretas que os tribunais nativos, entretanto consolidados pelo governo colonial, tiveram na organização social tradicional e, em particular, nos mecanismos de fusão da oposição segmentária. Facto curioso, e "perigoso", a identificação das alterações sociais ocorridas durante o colonialismo britânico não impediu Howell de contribuir para a identificação dos "valores fundamentais" dos nuer, como lhes chamou Evans-Pritchard.

O que está em confronto não é somente o lugar da história na antropologia, mas o grau de legitimidade da abstração no discurso científico - e por conseguinte, também, o tipo de história que se tem em mente. Existem alguns equívocos epistemológicos e contrassensos filosóficos na rejeição de princípio das generalizações, pois a sua supressão até às últimas consequências faria implodir o discurso antropológico e equivaleria a colocar uma pedra tumular sobre a academia. Como é óbvio, qualquer etnógrafo recorre inevitavelmente a diferentes formas de abstração, nem que seja a propósito das variações internas, sendo sempre possível pôr em causa o que quer que seja com base no argumento da desvirtuação da realidade empírica. O que sucede é que as generalizações que estão em sintonia com o power shift passam despercebidas, enquanto as que fazem sobressair consensos e continuidades culturais são relegadas para o plano da ideologia ocidental-colonial ou da invenção da tradição.

Esta questão atravessa o presente artigo de forma tão mais premente quanto o seu objetivo é evidenciar continuidades na história da antropologia, entendida num sentido muito pleno, segundo o qual a prática contemporânea também já é história. A tentativa de resgate dos antropólogos do passado, tal como Darnell a empreende, não poderá ser vista, afinal de contas, como mais uma manipulação discursiva, neste caso por um segmento da comunidade antropológica? Cada qual deverá responder no seu íntimo a esta questão, mas para o fazer com propriedade é necessário que haja um confronto com a imensidão, ou pelo menos uma noção da magnitude patrimonial do arquivo secular da história da antropologia, de forma a rejeitar os juízos apressados sobre três ou quatro figuras maiores. 
Os nuer dos séculos XIX e XX têm um imenso corpus etnográfico, que faz deles um caso clássico passível de continuar a ser estudado como tal ao longo das gerações, aconteça o que acontecer no Sul do Sudão. Apesar da conturbada situação política em que se encontram ainda hoje, provavelmente descobrirão um dia, com maior tranquilidade e decerto algum espanto, que são um dos povos africanos que mais tinta têm feito correr nas academias do mundo ocidental. É óbvio que há muitas considerações que transcendem a página atual da história da antropologia, quando está hoje mesmo em causa a violência, o sofrimento, a vida e a morte de um povo. Uma coisa é certa: num momento em que está cada vez mais esgotada a crítica dos heróis clássicos da antropologia como Evans-Pritchard, é tempo de ultrapassar ideias feitas e de aprofundar o diálogo entre a prática contemporânea e a história da disciplina.

\section{BIBLIOGRAFIA}

ARENS, W., 1983, "Evans-Pritchard and the prophets: comments on an ethnographic enigma”, Anthropos, 78: 1-16.

CLIFFORD, James, 1983, “On ethnographic authority”, Representations, 2: 118-146.

DARNELL, Regna, 2001, Invisible Genealogies: A History of Americanist Anthropology. Lincoln e Londres, University of Nebraska Press.

ERIKSEN, Thomas, 1993, Ethnicity and Nationalism: Anthropological Perspectives. Londres e Boulder, CO, Pluto Press.

EVANS-PRITCHARD, E.E., 1950, “Social anthropology: past and present", Man, 50 (198): 118-124.

—, 1954, "Foreword", em P.P. Howell, A Manual of Nuer Law: Being an Account of Customary Law; its Evolution and Development in the Courts Established by the Sudan Government. Londres, Oxford University Press, v-vii.

—, 1961, Anthropology and History. Manchester, Manchester University Press.

— 1969 [1940], The Nuer: A Description of the Modes of Livelihood and Political Institutions of a Nilotic People. Nova Iorque e Oxford, Oxford University Press.

FIRTH, Raymond, 1951, "Contemporary British social anthropology", American Anthropologist, 53: 474-489.

_-, 1964 [1954], "Social organization and social change", Essays on Social Organization and Values. University of London, The Athlone Press, 30-58.

— 1964 [1962], "Comment on 'Dynamic Theory' in social anthropology”, Essays on Social Organization and Values. University of London, The Athlone Press, 7-29.

FORTES, Meyer, and E. E. EVANS-PRITCHARD, 1983 [1940], "Introdução", Sistemas Políticos Africanos. Lisboa, Fundação Calouste Gulbenkian. 
HOWELl, Paul Philip, 1954, A Manual of Nuer Law: Being an Account of Customary Law; its Evolution and Development in the Courts Established by the Sudan Government. Londres, Oxford University Press.

HUTCHINSON, Sharon, 1996, Nuer Dilemmas: Coping with Money, War and the State. Berkeley, University of California Press.

— 2000, "Nuer ethnicity militarized", Anthropology Today, 16 (3): 6-13.

INGOLD, Tim, 2008, "Anthropology is not ethnography", Proceedings of the British Academy, 154, 69-92.

JOHNSON, Douglas H., 1994, The Nuer Prophets: A History of Prophecy from the Upper Nile in the Nineteenth and Twentieth Centuries. Oxford, Clarendon Press.

LEWIS, Herbert S., 1998, “The misrepresentation of anthropology", American Anthropologist, 100 (3): 716-731.

LIENHARDT, Godfrey, 1974, "E-P: a personal view: Sir Edward Evans-Pritchard 1902-1973”, Man, 9 (2): 299-304.

MALINOWSKI, Bronislaw, 1945, The Dynamics of Culture Change: An Inquiry into Race Relations in Africa. New Haven, Yale University Press.

ORTNER, Sherry, 1984, “Theory in anthropology since the Sixties", Comparative Studies in Society and History, 26 (1): 126-166.

—, 2006, Anthropology and Social Theory: Culture, Power and the Acting Subject. Durham e Londres, Duke University Press.

ROSALDO, Renato, 1986, "From the door of his tent: the fiedlworker and the inquisitor", em James Clifford e George E. Marcus (orgs.), Writing Culture: The Poetics and Politics of Ethnography. Berkeley, Los Angeles, Londres, University of California Press, 77-97.

SCHAPERA, Isaac, 1962, "Should anthropologists be historians?", Journal of the Royal Anthropological Institute of Great Britain and Ireland, 92 (2): 143-156.

SOUTHALL, Aidan, 1976, "Nuer and Dinka are people: ecology, ethnicity and logical possibility”, Man, n.s., 11 (4): 463-491.

VINCENT, Joan, 1990, Anthropology and Politics: Traditions, Visions, and Trends. Tucson, The University of Arizona Press.

The ghost of Evans-Pritchard: anthropology's dialogues with its own history - Frederico Delgado Rosa - Centro em Rede de Investigação em Antropologia, Faculdade de Ciências Sociais e Humanas da Universidade Nova de Lisboa, Portugal • fdelgadorosa@fcsh.unl.pt.

Through the reading of Sharon Hutchinson's monograph on the Nuer, this article explores the misunderstandings between contemporary anthropology and the modern classics. It tries to identify invisible genealogies that go back to the British functionalists, particularly to Evans-Pritchard, and minimizes the explicit oppositions between the present and the past of anthropology. It reveals that some classical notions are detectable in non-explicit ways among those who claim to reject them and, at the same time, that contemporary concerns have their roots in modern ethnographies. The author shows that static approaches - as the one by Evans-Pritchard on the Nuer - had a historical meaning and recalls that British social anthropology had its own theoretical and methodological answers to the transformations of African contexts under colonial rule.

KEYWORDS: History of anthropology, Nuer, Evans-Pritchard, functionalism, Sharon Hutchinson, colonialism. 